\title{
The Evaluation of Serum Levels of Erythrocyte Sedimentation Rate and C-reactive Protein with CA125 as Probable Predictive Factors of Malignancy in Adnexal Masses
}

\author{
Zeinab Nazari ${ }^{1}$, Afsane Rastegar ${ }^{1, *}$, Mehdi Nasouhi ${ }^{2}$, Elham Bani Mostafavi ${ }^{3}$, Fatemeh Montazer ${ }^{4}$ \\ 'Department of Medical Science, Mazandaran University of Medical Science, Mazandaran, IRAN. \\ 2Department of Medical Science, Babol University of Medical Science, Babol, IRAN. \\ ${ }^{3}$ Department of Medical Science, Mazandaran University of Medical Science, Mazandaran, IRAN. \\ ${ }^{4}$ Department of pathology, Gastrointestinal Cancer Research Center, Imam Hospital, Mazandaran university of Medical Sciences, Sari, IRAN.
}

\begin{abstract}
Background: Adnexa masses include ovarian masses, fallopian tubes and surrounding connective tissues and are among the most important and common disorders of women's science. The aim of this study was to investigate the levels of serum ESR and CRP changes along with CA125 in patients with adnexal tumors. Methods: This research was a crosssectional study. The statistical population consisted of all patients who referred to Imam Khomeini Hospital of Mazandaran University of Medical Sciences during 12 months from September 2016 to September 2017 with diagnosis of adnexal mass and undergoing surgery. The sample size was 100 people who were selected through convenience sampling method. The method of data collection was such that a blood sample was taken from all patients who were candidates for adnexa masses surgery and kept at room temperature for $30 \mathrm{~min}$ and then centrifuged for $10 \mathrm{~min}$ at $4000 \mathrm{rpm}$. Data were analyzed using Mann-Whitney U test, correlation coefficient and logistic regression analysis. Results: The findings showed that elevated levels of CA125, ESR and CRP were not significantly correlated
\end{abstract}

with tumor type and could not be used for screening alone. However, in cases of malignant tumors, its increased levels may indicate a higher staging of the tumor. Conclusion: According to the results, evaluation of the level of tumor marker CA125 and inflammatory markers of ESR and CRP in malignant tumor can be used to determine appropriate diagnostic therapeutic measures

Key words: Adnexal masses, CA125, C-reactive protein, Erythrocyte sedimentation rate.

Correspondence

Afsane Rastegar,

Assistant of gynecology, Department of Medical Science, Mazandaran University of Medical Science, Mazandaran, IRAN.

Phone: 989113556598

Email: Afsanerastegar27@gmail.com

DOI: 10.5530/jyp.2019.11.61

\section{INTRODUCTION}

Adnexa masses include ovarian masses, fallopian tubes and surrounding connective tissues and are among the most important and common disorders of women's science (gynecology). ${ }^{1}$ These masses have gynecology and non- gynecology and their causes are variable from simple luteal cysts to ovarian cancers and intestinal abscesses. Adnexal examination has low sensitivity in detecting these types of masses and the absence of positive findings in the examination of patients should not prevent further studies. ${ }^{2}$ Ovarian cancer is considered as the seventh cancer in the world ${ }^{3}$ and is the second most common and fatal cancer in gynecology. The cause of this is the potential of this member in relation to the emergence of neoplasm. Given the favorable disease prognosis, if diagnosed in the early stages, the presence of the suitable screening tests has a significant effect on the improvement of the fate of these patients and significantly reduces the mortality rate in these patients, but there is still no biomarker with sufficient sensitivity and specificity to this effect. ${ }^{4}$ There is no specific biomarker for the diagnosis of ovarian cancer. An antigen of 125 (CA-125), discovered in $1983,{ }^{5}$ is a high molecular weight glycoprotein which is produced during the fetal period of cellular epithelium ${ }^{6}$ and through the rise of the anti-tumor antibodies at the time of infusion to a heterologous animal was detected and identified in the serum. One of the possible mechanisms involved in ovarian cancer is inflammation. Inflammation can affect ovulation events as the inflammatory reaction occurs during the ovulation process. ${ }^{7}$ Ovulation is an inflammatory process that involves the recovery and repair of the ulcers and repeated ovulation is known to be one of the underlying causes of ovarian cancer. Inflammation causes cellular damage, oxidative stress and increased cytokines and prostaglandins, all of which can cause mutations. In fact, chronic inflammation, due to the lack of regulation of inflammatory cytokines, increases the chances of cell growth, the transformation of increased cells to malignant ones and the maintenance of these malignant cells. ${ }^{8}$ Considering that early diagnosis of genital cancers is a vital step in ensuring women's health, new knowledge on screening and early diagnosis of pre-cancerous and cancerous diseases is needed for physicians. The requirement for the widespread use of screening methods is their sufficient sensitivity and high specificity, low cost and non-invasive nature. ${ }^{9}$ Nowadays, for the differentiation of benign adnexal masses from malignant ones, a combination of clinical imaging criteria such as age, the patient's menopausal status and the CA-125 marker are used..$^{10}$ Therefore, according to the available data and information indicating the limited studies conducted especially in our country (Iran) regarding the finding of biomarkers and parameters that can predict and recognize the adnexal tumors and considering the role of inflammation in the incidence of ovarian cancer and since inflammatory biomarkers such as ESR and CRP are available in a simple, inexpensive and accessible way, we aimed to study the level of changes in serum ESR and CRP along with CA-125 in patients with adnexal tumors, so that

This is an open access article distributed under the terms of the Creative Commons Attribution-NonCommercial-ShareAlike 4.0 License, which allows others to remix, tweak, and build upon the work non-commercially, as long as the author is credited and the new creations are licensed under the identical terms. 
in the future, we can provide more reliable diagnostic solutions for the medical community.

\section{METHOD}

The present study was a cross-sectional one. The statistical population consisted of all patients who referred to Imam Khomeini Hospital of Mazandaran University of Medical Sciences during 12 months from September 2016 to September 2017 with diagnosis of adnexal mass and undergoing surgery. The research samples were selected from all the patients based on the clinical findings of the diagnosis of primary and probable adnexal masses according to the inclusion criteria (20-80-yearold women with adnexal tumor) and exclusion criteria pregnant and lactating women, dissatisfaction with Presence in the study, inflammatory and infectious diseases in the previous week and history of rheumatic disease) using easy and convenience sampling method. Sample size: According to Britton Trabert et al. 2014, in which the serum CRP level was reported high in $42 \%$ of patients with ovarian cancer and at a $95 \%$ confidence level and a maximum error of $20 \%$ and assuming a drop of $10 \%$ during study, the minimum sample size of 100 is estimated. The method of data collection was such that a blood sample was taken from all patients who were candidates for adnexa masses surgery and kept at room temperature for $30 \mathrm{~min}$ and then centrifuged for $10 \mathrm{~min}$ at $4000 \mathrm{rpm}$. Data were analyzed using Mann-Whitney $U$ test, correlation coefficient and logistic regression analysis. The sera were stored in a refrigerator at a temperature of $80^{\circ} \mathrm{C}$. The levels of CRP and ESR along with CA-125 of patients were measured by Toshiba Acute auto-analyzer and using Immuno-turbidimetric method. All pathology samples were evaluated by a pathologist from the pathology group of Mazandaran University of Medical Sciences. The FIGO surgical staging system was used for ovarian cancer stage and histopathology was assessed according to the WHO guidelines. Subsequently, patients were divided into appropriate groups based on postoperative diagnosis and surgical categorization. Demographic data of the subjects were also recorded in the designed questionnaire. To describe the quantitative data, the mean and standard deviation and for qualitative data frequency and percentage were used. Chi2 test was used to compare the levels of ESR, CRP and CA125 in different types of adnexal tumors. The correlation test and calculating Spearman coefficient after Categorizing biomarker values were also used to study the relationship between stage tumor and different levels of each biomarker. In all cases of statistical descriptions appropriate tables and charts were used. The cut-off rate for CRP was considered $5 \mathrm{mg} / \mathrm{dl}$ and for $\mathrm{ESR}=20 \mathrm{mg} / \mathrm{dl}$ (taking into account age). All statistical analyzes of this study were performed by SPSS version 21 and $P$-value less than 0.05 was considered statistically significant. According to the above Table, the mean age of patients with benign tumors was 37.24 \pm 12.43 years and patients with malignant tumors was $57.92 \pm 10.37$ years, which were significantly different based on the results $(P<0.001)$. Table 3 shows the frequency of ovarian masses in the sample (See consort flow Diagram 1)

\section{RESULTS}

In Table 1 , the age range of the sample (100 people) is presented. The relationship between the age of patients in the study and the type of ovarian mass is presented in Table 2, 4 shows that among patients with pathologic finding of malignant adnexal mass, 26 (47.26\%) cases were in stage 1 of disease (based on the TNM staging provided by the International Federation of Gynecology and Obstetrics (FIGO), 19 cases were in stage 2 of the disease (34.53\% of cases) and 10 cases in the stage 3 of the disease (18.18\% of cases). None of the patients in the study with malignant tumors were in stage 4 disease (based on stage). The above table showed that among patients with malignant tumors, all diagnosed cases in stage 3 were over 50 years old $(10(100 \%)$ ), which was statistically

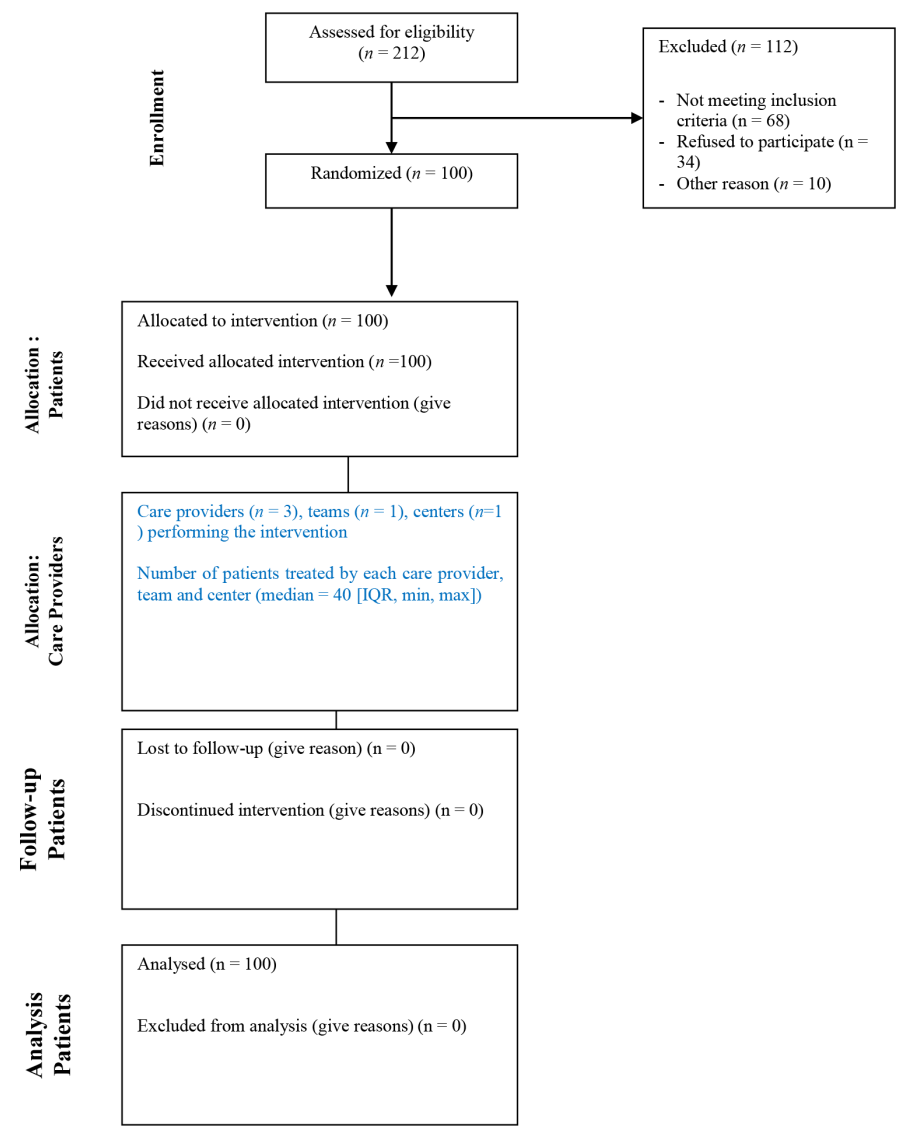

Diagram 1: Modified consort flow diagram for individual randomized controlled trials of nonpharmacologic treatments.

An extra box per intervention group relating to care providers and centers has been added.

significant $(p<0.001)$. The lower stages were observed at lower ages. The average CA125 level was $55.47 \pm 34.76(\min 4$, $\max 120$, median 36.6$)$. In terms of the ratio of inflammatory biomarkers and tumor markers, the frequency of elevated CA125 was about $44.7 \%$, while the two criteria for ESR and CRP had the same frequency in either normal or increased state. The mean mass size in patients with malignant tumors was $12.01 \pm 18.17$ centimeters and in patients with benign tumor was $10.39 \pm 14.30$ centimeters, which did not show a significant difference $(p$ value $=0.435)$.

Table 9 showed that there was a significant difference between the serum CA125 level and the specific diagnosis of tumorigenic diseases $(p=0.001)$, so that the serum levels of CA125 in serous adenocarcinoma and papillary had the highest levels. Relationship between tumor markers of CA125 and malignant mass staging was significant $(p<0.001)$, so that in the higher stages (2 and 3 ) normal levels of biomarker are less expected. In the table above, the mean age of elevated ESR levels was not statistically different from the normal cases $(p$ value $=0.920$ ). In the case of inflammatory biomarkers including ESR and CRP, elevated levels of both in malignant cases were seen but not statistically significant $(p$ value $=$ 0.422).

According to the above tables, in relation to serum levels of ESR and CRP, normal levels have been observed in various stages of malignant tumorigenic disease, which is statistically significant in relation to elevated levels $(P$ value $=0.050)$. In terms of age distribution, the serum ESR level did not have a significant relationship between normal or elevated levels with different age groups ( $p$ value $=0.654$ ). 
Table 1: Age range of the sample.

\begin{tabular}{ccc}
\hline Variable & Age range & Frequency \\
\hline \multirow{3}{*}{ Age } & Less than 30 years & $19(19 \%)$ \\
& Between 31-50 years & $46(46 \%)$ \\
& More than 51 years & $35(35 \%)$ \\
\hline
\end{tabular}

Table 2: Relationship between patient's age and type of ovarian mass.

\begin{tabular}{lccccc}
\hline \multicolumn{2}{c}{ Variable } & \multicolumn{3}{c}{ Age range (year) } & $p$-value \\
\cline { 3 - 5 } & & $\geq 30$ & $31-50$ & $\leq 51$ & $<0.0001$ \\
\cline { 3 - 5 } $\begin{array}{l}\text { Type of } \\
\text { tumor }\end{array}$ & Benign & $6(31.6 \%)$ & $32(69.6 \%)$ & $7(20 \%)$ & \\
\hline
\end{tabular}

Table 3: Frequency of ovarian masses in the sample.

\begin{tabular}{|c|c|c|}
\hline \multicolumn{2}{|r|}{ Variable } & Frequency \\
\hline \multirow{6}{*}{ Benign mass } & serous cystadenoma & $(8 \%) 8$ \\
\hline & functional cyst & $(8 \%) 8$ \\
\hline & mature cystic teratoma & $(2 \%) 2$ \\
\hline & serous borderline tumor & $(9 \%) 9$ \\
\hline & mucinous borderline tumor & $(6 \%) 6$ \\
\hline & leiomyoma & $(11 \%) 11$ \\
\hline \multirow{11}{*}{ Malignant mass } & fibrotecoma & $(1 \%) 1$ \\
\hline & serous cystadenocarcinoma & $(24 \%) 24$ \\
\hline & mucinous cystadenocarcinoma & $(2 \%) 2$ \\
\hline & ovarian dysgerminoma & $(6 \%) 6$ \\
\hline & immature teratoma & $(6 \%) 6$ \\
\hline & mix germcell tumor & $(2 \%) 2$ \\
\hline & $\begin{array}{c}\text { ovarian juvenile granulosa cell } \\
\text { tumor }\end{array}$ & $(2 \%) 2$ \\
\hline & mixed mullerian tumor & $(1 \%) 1$ \\
\hline & $\begin{array}{c}\text { papillary serous } \\
\text { cystadenocarcinoma }\end{array}$ & $(5 \%) 5$ \\
\hline & endometrioid carcinoma & $(5 \%) 5$ \\
\hline & krukenberge & $(2 \%) 2$ \\
\hline
\end{tabular}

Table 4: Staging of tumors in patients under study.

\begin{tabular}{ccc}
\hline Stage & Level & Frequency \\
\hline \multirow{2}{*}{$\mathrm{I}(n=26)$} & $\mathrm{A}$ & $16(29.09 \%)$ \\
& $\mathrm{B}$ & $8(14.54 \%)$ \\
& $\mathrm{C}$ & $2(3.63 \%)$ \\
$\mathrm{II}(n=19)$ & $\mathrm{A}$ & $9(16.36 \%)$ \\
& $\mathrm{B}$ & $4(7.27 \%)$ \\
& $\mathrm{C}$ & $6(10.90 \%)$ \\
$\mathrm{III}(n=10)$ & A & $4(7.27 \%)$ \\
& B & $5(9.09 \%)$ \\
& C & $1(1.81 \%)$ \\
\hline
\end{tabular}

Table 5: Relationship between patient's age and ovarian mass staging.

\begin{tabular}{cccccc}
\multirow{2}{*}{ Variable } & \multicolumn{3}{c}{ Age range (year) } & $p$-value \\
\cline { 3 - 5 } & & $\geq 30$ & $31-50$ & $\leq 51$ & $<0.001$ \\
\hline \multirow{3}{*}{ Staging } & I & $8(30.76 \%)$ & $14(53.84 \%)$ & $14(73.68 \%)$ & \\
& II & $5(31.26 \%)$ & $0(0 . \%)$ & $4(15.38 \%)$ & \\
& III & $0(0 . \%)$ & $0(0 . \%)$ & $10(100 \%)$ & \\
\hline
\end{tabular}

Table 6: Frequency of normal and elevated CA125, ESR and CRP cases in patients with benign tumors.

\begin{tabular}{|c|c|c|}
\hline \multicolumn{2}{|c|}{ Biomarkers } & \multirow{2}{*}{$\begin{array}{c}\text { Frequency } \\
25(55.3 \%)\end{array}$} \\
\hline CA125 & Normal & \\
\hline & Elevated & $20(44.7 \%)$ \\
\hline \multirow[t]{2}{*}{ ESR } & Normal & $28(61.7 \%)$ \\
\hline & Elevated & $17(38.3 \%)$ \\
\hline \multirow[t]{2}{*}{ CRP } & Normal & $28(61.7 \%)$ \\
\hline & Elevated & $17(38.3 \%)$ \\
\hline
\end{tabular}

Table 7: Relationship between CA125 of patients in the study and ovarian mass.

\begin{tabular}{lcccc}
\hline \multirow{2}{*}{ Variable } & \multicolumn{2}{c}{ CA125 } & p-value \\
\cline { 3 - 4 } & & Normal & Elevated & $<0.0001$ \\
\cline { 3 - 4 } Type of & Benign & $20(54.1 \%)$ & $25(39.7 \%)$ & \\
tumor & Malignant & $17(45.9 \%)$ & $38(60.3 \%)$ & \\
\hline
\end{tabular}

Table 8: The mean age and level of CA125 in patients participating in the study.

\begin{tabular}{ccc}
\hline Variable & Mean \pm SD & Range (year) \\
\hline Age & $45.02 \pm 13.86$ & $17-72$ years \\
CA125 & $55.47 \pm 34.76$ & $4-120$ \\
\hline
\end{tabular}

Table 9: Relationship between CA125 of patients in the study and staging of ovarian mass.

\begin{tabular}{lcccc}
\hline \multicolumn{2}{c}{ Variable } & \multicolumn{2}{c}{ CA125 } & $P$-value \\
\hline \multirow{4}{*}{ Staging } & I & Normal & Elevated & \\
& & $11(405)$ & $15(60 \%)$ & $<0.001$ \\
& II & $0(0 \%)$ & $19(100 \%)$ & \\
& III & $1(10 \%)$ & $9(90 \%)$ & \\
\hline
\end{tabular}

Table 10: Mean age of patients by ESR.

\begin{tabular}{cccc}
\hline \multirow{2}{*}{ Age (year) } & \multicolumn{2}{c}{ ESR } & \multirow{2}{*}{$P$-value $95 \% \mathrm{Cl}$} \\
\cline { 2 - 3 } & Normal & Elevated & \\
\hline $\begin{array}{c}\text { Standard deviation } \\
\pm \text { Mean }\end{array}$ & $44.13 \pm 88.40$ & $14.45 \pm 16.45$ & 0.920 \\
\hline
\end{tabular}

Table 11: Relationship between ESR of patients in the study and type of ovarian mass.

\begin{tabular}{ccccc}
\hline \multicolumn{2}{c}{ Variable } & \multicolumn{2}{c}{ ESR } & p-value \\
\cline { 3 - 5 } & & Normal & Elevated & \\
\hline \multirow{2}{*}{$\begin{array}{l}\text { Type of } \\
\text { tumor }\end{array}$} & Benign & $25(50 \%)$ & $20(40 \%)$ & 0.422 \\
\hline
\end{tabular}


Table 12: Relationship between CRP of patients in the study and type of ovarian mass.

\begin{tabular}{|ccccc}
\hline \multirow{2}{*}{ Variable } & \multicolumn{2}{c}{ ESR } & p-value \\
\cline { 3 - 5 } & & Normal & Elevated & \\
\hline \multirow{2}{*}{ Type of tumor } & Benign & $25(50 \%)$ & $20(40 \%)$ & 0.422 \\
& Malignant & $25(50 \%)$ & $30(60 \%)$ & \\
\hline
\end{tabular}

Table 13: Relationship between ESR of patients in the study and staging of ovarian mass.

\begin{tabular}{lcccc}
\hline \multicolumn{2}{c}{ Variable } & \multicolumn{2}{c}{ CA125 } & P-value \\
\hline \multirow{4}{*}{ Staging } & I & Normal & Elevated & \\
& & $10(40 \%)$ & $16(60 \%)$ & 0.050 \\
& II & $11(55.6 \%)$ & $8(44.4 \%)$ & \\
& III & $1(10 \%)$ & $9(90 \%)$ & \\
\hline
\end{tabular}

Table 14: Relationship between CRP of patients in the study and ovarian and staging of ovarian mass.

\begin{tabular}{lcccc}
\hline \multicolumn{2}{c}{ Variable } & \multicolumn{2}{c}{ CA125 } & $P$-value \\
\hline \multirow{4}{*}{ Staging } & I & Normal & Elevated & \\
& & $11(40 \%)$ & $16(60 \%)$ & 0.050 \\
& II & $11(55.6 \%)$ & $8(44.4 \%)$ & \\
& III & $1(10 \%)$ & $9(90 \%)$ & \\
\hline
\end{tabular}

Table 15: The relationship between patients' age and their ESR level.

\begin{tabular}{ccccc}
\hline \multirow{2}{*}{ Variable } & \multicolumn{2}{c}{ ESR } & \multirow{2}{*}{ P-value } \\
\cline { 3 - 4 } & & Normal & Elevated & \\
\hline \multirow{2}{*}{ Age } & Less than 30 years & $8(16 \%)$ & $11(22 \%)$ & \\
(year) & 31-50 years & $25(50 \%)$ & $21(42 \%)$ & 0.654 \\
& Up to 51 years & $17(34 \%)$ & $18(36 \%)$ & \\
\hline
\end{tabular}

Table 16: Mean of patients' CA125 by ESR.

\begin{tabular}{cccc}
\hline \multirow{2}{*}{ Age (year) } & \multicolumn{2}{c}{ ESR } & $P$-value $95 \% \mathrm{Cl}$ \\
\cline { 2 - 4 } & Normal & Elevated & \\
\hline $\begin{array}{c}\text { Standard deviation } \\
\pm \text { Mean }\end{array}$ & $52.32 \pm 00.81$ & $58.36 \pm 94.60$ & 0.321 \\
\hline
\end{tabular}

The level of serum CA125 in elevated ESR conditions was not statistically significant $(p$ value $=0.321)$, despite a higher mean of ESR levels $(52.22$ \pm 00.81 vs. $58.94 \pm 36.60)$.

\section{DISCUSSION}

The aim of this study was to determine the levels of serum ESR and CRP along with CA-125 in patients with adnexal tumors. According to the findings, the elevated levels of CA125, ESR and CRP have no significant relationship with tumor type and can't be used for screening alone, but in cases of diagnosed malignant tumors, its elevated levels can indicate a higher staging of tumor formation. The results of this study are in line with the results of researches by Watrowski and his colleagues, ${ }^{11}$ HeflerFrischmuth. ${ }^{12}$ Hefler et al..$^{10}$ and McSorley et al. ${ }^{13}$ According to Terzic et al. in 2013, entitled the study of diagnostic guidelines for patients with adnexal masses in 2 years and on 689 patients with adnexal mass, the mean ESR in patients with adnexa masses was $35.17 \pm 27.66$. In this study, there was a significant difference in the amount of ESR and CA125 in tumor types. It was also concluded that ESR levels could predict the nature and structure of the adnexal tumors. However, this prediction would be feasible by having other parameters such as CEA levels, ultrasound qualities and malignant risk index (RMI), which was not statistically significant in our study of ESR in patients with ovarian mass. However, the association of ESR in the study with the staging of ovarian mass is significant and can be used to determine the severity of the malignant tumor. ${ }^{14}$ In a descriptive-analytic study, presented by Dr. Mohammad Vasei et al. in case - control form, with the title of clinical symptoms and risk factors of ovarian cancer in patients referring to Shahid Akbar Abadi and Rasoul Hospital of Tehran on 89 patients with ovarian cancer the results were as follows: The prevalence of ovarian cancer in this study was $67.6 \%$. There were no initial clinical symptoms in $37.3 \%$ of subjects. The frequency of sexual cord tumors was $8.8 \%$, germ cell tumors were $2.7 \%$ and there was a significant correlation between the amount of tumor marker CA125 and the stage of the disease, which was also consistent with our study that tumor marker was associated with the staging of malignant tumors which was statistically significant but despite the high level of CA125 in malignant cases, it wasn't statistically significant, which was probably due to the low number of cases. ${ }^{15}$ According to a study by Mcnsurrell et al. the risk of ovarian cancer is positively associated with an increase in CRP concentrations. In this study, 160 patients with ovarian cancer and the same control group who were matched for age, race menopause status and were evaluated for CRP level. Finally, it was found in women with CRP more than 3 times the upper limit of normal, the risk of ovarian cancer is $70 \%$ higher than that of women with CRP below normal percentile, but in our study there was no significant relationship between CRP and tumor type, however, elevated serum levels in the higher stages of malignancy were considered statistically significant. No relationship between the level and type of tumor may be due to the lack of proper alignment. ${ }^{13}$ Also, study conducted by Hefler-Frischmuth et al. in 2009, entitled the investigation of the application of CRP for differential diagnosis of uterine masses on 576 patients with benign tumors and 242 patients with malignant tumors, the presence of high serum CRP was associated with the presence of malignant tumors of the ovary, which this association is independent from CA125 serum and age of the patients and can therefore be used as an additional diagnostic marker for differential diagnosis of ovarian masses, while in our study this index was not significant. ${ }^{12}$ The results of the Hefller and associates' study also report the relationship between the level of CRP and the development of the disease, as well as the remaining tumor after surgery were consistent with our findings and one of the uses of inflammatory markers in diagnosed cases of malignant tumors is the predictability of the disease stage. However, in the Hefller's study, the level of CRP did not correlate with the histological grade, age and CA-125 level. ${ }^{9}$

\section{CONCLUSION}

In the end, it should be noted that the current research has been accompanied by limitations including the number of samples and the lack of matching and non-randomization, as well as the limitations of laboratory kits to assess the biomarkers' level. It is suggested that in other studies, assessing the level of biomarkers, in the presence of control group that has been matched and also the study with the number of more samples to be examined and of practical suggestions is the evaluation of tumor marker CA125 levels and inflammatory markers ESR and CRP in malignant tumor to determine the appropriate diagnostic- therapeutic measures 


\section{CONFLICT OF INTEREST}

The authors declare no conflict of interest.

\section{REFERENCES}

1. Suh-Burgmann E, Kinney W. The Value of Ultrasound Monitoring of Adnexal Masses for Early Detection of Ovarian Cancer. Front Oncol. 2016;6:25.

2. Biggs WS, Marks ST. Diagnosis and Management of Adnexal Masses. American Family Physician. 2016;93(8):676-81.

3. Pérez-López FR, Chedraui P, Troyano-Luque JM. Peri-and post-menopausal incidental adnexal masses and the risk of sporadic ovarian malignancy: New insights and clinical management. Gynecological Endocrinology. 2010;26(9): 631-43.

4. Hoskins ER, Hood BL, Sun M, Krivak TC, Edwards RP, Conrads TP. Proteomic analysis of ovarian cancer proximal fluids: Validation of elevated peroxiredoxin 1 in patient peripheral circulation. PLoS One. 2011;6(9):e25056.

5. Moore RG, Brown AK, Miller MC, Skates S, Allard WJ, Verch T, et al. The use of multiple novel tumor biomarkers for the detection of ovarian carcinoma in patients with a pelvic mass. GynecolOncol. 2008;108(2):402-8.

6. Canney PA, Moore M, Wilkinson PM, James RD. Ovarian cancer antigen CA125: A prospective clinical assessment of its role as a tumour marker. British Journal of Cancer. 1984;50(6):765-9.
7. Shan W, Liu J. Inflammation: A hidden path to breaking the spell of ovarian cancer. Cell Cycle. 2009;8(19):3107-11.

8. McAlpine JN, Lisonkova S, Joseph KS, McComb PF. Pelvic inflammation and the pathogenesis of ovarian cancer: A cohort study. International Journal of Gynecological Cancer. 2014;24(8):1406-13.

9. Kingsmore SF. Multiplexed protein measurement: Technologies and applications of protein and antibody arrays. Nat Rev Drug Discov. 2006;5(4):310-20.

10. Hefler LA, Concin N, Hofstetter G, Marth C, Mustea A, Sehouli J, et al. Serum $\mathrm{C}$-reactive protein as independent prognostic variable in patients with ovarian cancer. Clin Cancer Res. 2008;14(3):710-4

11. Watrowski R, Zeillinger R. Simple laboratory score improves the preoperative diagnosis of adnexal mass. Tumor Biology. 2016;37(4):4343-9.

12. Hefler-Frischmuth K, Hefler LA, Heinze G, Paseka V, Grimm C, Tempfer CB. Serum $C$-reactive protein in the differential diagnosis of ovarian masses. Eur $J$ ObstetGynecolReprod Biol. 2009;147:65-8.

13. McSorley MA, Alberg AJ, Allen DS, Allen NE, Brinton LA, Dorgan JF, et al. C-reactive protein concentrations and subsequent ovariancancer risk. ObstetGynecol. 2007;109(4):933-41.

14. Terzic MM, Dotlic J, Likic I, Ladjevic N, Brndusic N, Arsenovic N, et al. Current diagnostic approach to patients with adnexal masses: Which tools are relevant in routine praxis?. Chin J Cancer Res. 2013;25(1):55-62.

15. Vaseie M, Matin S, Alavi S. The Evaluation of Ovarian Cancer Symptoms and Risk factors in Patients of Hazrat-e-Rasool and ShahidAkbarabadi Hospitals. Ann Mil Health Sci Res. 2010;8(2):112-7.

Article History: Submission Date : 09-06-2019; Revised Date : 28-06-2019; Acceptance Date : 16-07-2019.

Cite this article: Nazari Z, Rastegar A, Nasouhi M, Mostafavi EB, Montazer F. The Evaluation of Serum Levels of Erythrocyte Sedimentation Rate and C-reactive Protein with CA125 as Probable Predictive Factors of Malignancy in Adnexal Masses. J Young Pharm. 2019;11(3):304-8. 